\title{
A Survey of Same-Sex Sexual Experiences Among Psychiatric Inpatients With and Without Borderline Personality Symptomatology
}

To the Editor: In comparison to the general population, individuals with borderline personality disorder appear to exhibit a higher prevalence of sexual experiences with members of the same sex, ${ }^{1-5}$ with psychiatric inpatients exhibiting higher rates than psychiatric outpatients, and male psychiatric outpatients exhibiting higher rates than female psychiatric outpatients. In this study, we investigated the prevalence of same-sex sexual experiences among psychiatric inpatients, comparing those with versus without borderline personality disorder symptomatology according to 3 different self-report measures for this disorder.

Method. Study candidates were 167 men and women admitted to an urban psychiatric inpatient facility. Exclusion criteria included intellectual, medical, psychiatric, or cognitive impairment of a severity to diminish the individual's ability to complete a survey. Fourteen individuals were excluded (3 vision problems, 4 intellectually disabled/illiterate, 4 psychotic, 3 malingering). Of those approached, 145 (95\%) agreed to participate: 55 men and 89 women (1 participant declined to report gender), with a mean age of 38.06 years $(\mathrm{SD}=13.06)$. The majority self-identified as white $(74 \%)$, with $16 \%$ black. The majority $(87 \%)$ had at least completed high school. Approximately $41 \%$ reported never having been married, with $18 \%$ married, $27 \%$ divorced, $10 \%$ separated, and $3 \%$ widowed.

At admission, each candidate was invited to complete an anonymous survey that contained the query, "How many same-sex partners have you had in your lifetime?" with response options of $\geq 0-5$. The survey also queried about borderline personality disorder using 3 self-report diagnostic measures: the Personality Diagnostic Questionnaire $-4^{6}$ (Cronbach $\alpha=0.74$ ), the McLean Screening Inventory for Borderline Personality Disorder ${ }^{7}$ (Cronbach $\alpha=0.78$ ), and the screening instrument for the Structured Clinical Interview for DSM-IV Axis II Personality Disorders ${ }^{8}$ (Cronbach $\alpha=0.86$ ). The elements of informed consent were provided on the cover page of the survey, and completion of the survey was assumed to function as informed consent (stated on the cover page). The project was approved by the sponsoring hospital's institutional review board.

Results. Among participants, 59\% reported at least 1 same-sex sexual experience. Using $\chi^{2}$ analyses, we examined participants with versus without borderline personality disorder according to diagnostic cutoffs in terms of this behavior (Table 1). None of these comparisons were statistically significant (all $P>.05$ ). Moreover, dimensional scores on the measures of borderline personality disorder also were not statistically significantly correlated with a history of same-sex experiences (see Table 1).

\begin{tabular}{|c|c|c|c|c|c|c|}
\hline \multirow[b]{2}{*}{ Measure } & \multicolumn{2}{|c|}{$\begin{array}{c}\text { Borderline } \\
\text { Personality Disorder } \\
\text { Symptomatology, } \%\end{array}$} & \multirow[b]{2}{*}{$x^{2}$} & \multirow[b]{2}{*}{$P$} & \multirow[b]{2}{*}{$r$} & \multirow[b]{2}{*}{$P$} \\
\hline & Absent & Present & & & & \\
\hline$\overline{P D Q}-4$ & 50.8 & 65.8 & 3.21 & .073 & 0.10 & .224 \\
\hline MSI-BPD & 52.9 & 65.3 & 2.21 & .138 & 0.07 & .440 \\
\hline SCID-II & 58.1 & 60.3 & 0.07 & .793 & 0.12 & .174 \\
\hline \multicolumn{7}{|c|}{$\begin{array}{l}\text { Abbreviations: MSI-BPD = McLean Screening Inventory for Borderline } \\
\text { Personality Disorder, PDQ-4 = Personality Diagnostic Questionnaire-4, } \\
\text { SCID-II=Structured Clinical Interview for DSM-IV Axis II Personality } \\
\text { Disorders. }\end{array}$} \\
\hline
\end{tabular}

Stated simply, while inpatients with borderline personality disorder symptomatology appear to have higher rates of same-sex sexual experiences than the general population, surprisingly, these do not appear to exceed the rates encountered among psychiatric inpatients without this personality disorder. To our knowledge, this is a novel finding in the current literature and suggests that mental disorders, in general, may predict higher rates of samesex sexual experiences.

This study has a number of potential limitations, including the small sample size, self-report nature of the data, and use of an urban inpatient psychiatric sample (ie, findings may not generalize to psychiatric inpatients in 
nonurban settings or psychiatric outpatients). However, findings indicate that while psychiatric inpatients with borderline personality disorder symptomatology evidence higher rates of same-sex sexual experiences than the general population, these rates are not higher than those encountered among psychiatric inpatients without borderline personality disorder symptomatology.

\section{REFERENCES}

1. Sansone RA, Sansone LA. Sexual behavior in borderline personality: a review. Innov Clin Neurosci. 2011;8(2):14-18. PubMed

2. Zubenko GS, George AW, Soloff $\mathrm{PH}$, et al. Sexual practices among patients with borderline personality disorder. Am J Psychiatry. 1987;144(6):748-752. PubMed doi:10.1176/ajp.144.6.748

3. Reich DB, Zanarini MC. Sexual orientation and relationship choice in borderline personality disorder over ten years of prospective follow-up. J Pers Disord. 2008;22 (6):564-572. PubMed doi:10.1521/pedi.2008.22.6.564

4. Singh D, McMain S, Zucker KJ. Gender identity and sexual orientation in women with borderline personality disorder. J Sex Med. 2011;8(2):447-454. PubMed doi:10.1111/j.1743-6109.2010.02086.x

5. Sansone RA, Chu JW, Wiederman MW. Sexual behavior and borderline personality disorder among female psychiatric inpatients. Int J Psychiatry Clin Pract. 2011;15 (1):69-73. PubMed doi:10.3109/13651501.2010.507871

6. Hyler SE. Personality Diagnostic Questionnaire, PDQ-4. New York, NY: New York State Psychiatric Institute; 1994.

7. Zanarini MC, Vujanovic AA, Parachini EA, et al. A screening measure for BPD: the McLean Screening Instrument for Borderline Personality Disorder (MSI-BPD). J Pers Disord. 2003;17(6):568-573. PubMed doi:10.1521/pedi.17.6.568.25355

8. First MB, Gibbon M, Spitzer RL, et al. Structured Clinical Interview for DSM-IV Axis II Personality Disorders, (SCID-II). Washington, DC: American Psychiatric Press, Inc; 1997.

Randy A. Sansone, MD $^{\mathrm{a}}$

Randy.sansone@khnetwork.org

Martin Sellbom, $\mathbf{P h D}^{\mathrm{b}}$

Douglas A. Songer, MD $^{\mathrm{c}}$

${ }^{a}$ Departments of Psychiatry and Internal Medicine, Wright State University School of Medicine, Dayton, and Kettering Medical Center, Kettering, Ohio

${ }^{b}$ Research School of Psychology, The Australian National University, Canberra, Australia

${ }^{\mathrm{c}}$ Department of Psychiatry, Wright State University School of Medicine and Premier Health Partners, Dayton, Ohio

Potential conflicts of interest: None reported.

Funding/support: None reported.

Published online: March 31, 2016.

Prim Care Companion CNS Disord 2016;18(2):doi:10.4088/PCC.15l01876

(C) Copyright 2016 Physicians Postgraduate Press, Inc. 